\title{
Síndrome de Vohwinkel o queratodermia hereditaria mutilante
}

Vohwinkel syndrome or keratoderma hereditarium mutilans

\section{Vania Florero', Juliana Martínez del Sel², Diego Navajas³, Myriam Dahbar², Miguel Allevato $^{4}$}

1. Médica dermatologa, ex becaria de segundo año, División de Dermatología, Hospital de Clínicas José de San Martín, Buenos Aires, Argentina

2. Médica dermatóloga de planta, División de Dermatología, Hospital de Clínicas José de San Martín, Buenos Aires, Argentina

3. Médico dermatólogo, Ex jefe de residentes, División de Dermatología, Hospital de Clínicas José de San Martín, Buenos Aires, Argentina

4. Médico dermatólogo, jefe, División de Dermatología, Hospital de Clínicas José de San Martín; profesor titular de Dermatología, Universidad de Buenos Aires, Buenos Aires, Argentina

\section{RESUMEN}

El síndrome de Vohwinkel es una genodermatosis de herencia autosómica dominante ocasionada por mutaciones en el gen GJB2, localizado en el locus 13q11-q12, que codifica para la conexina 26. Forma parte del grupo de las conexinopatías.

El síndrome de Vohwinkel se manifiesta desde la infancia y se hace más evidente en la edad adulta, y tiene predilección por el sexo femenino y la raza caucásica. Clínicamente, se caracteriza por una tríada: queratodermia palmo-plantar difusa, transgrediens, “en panal de abejas”; pápulas queratósicas lineales o “en estrella de mar” en codos y rodillas; y bandas fibrosas constrictivas en los dedos de manos y pies (pseudoainhum), a lo que se asocia hipoacusia moderada a grave.

Se presenta una paciente con síndrome de Vohwinkel, con queratodermia palmoplantar, bandas fibrosas constrictivas (pseudoainhum), pápulas queratósicas lineales e hipoacusia grave.

PALABRAS CLAVE: queratodermia palmo-plantar, sordera, genética, conexinas, síndrome de Vohwinkel

\section{SUMMARY}

Vohwinkel syndrome is an autosomal dominant inherited genodermatosis caused by mutations in the GJB2 gene located in 13q11-q12 that encodes connexin 26.

Vohwinkel syndrome manifests in infants and becomes more evident in adulthood. The disease mostly occurs in white women. The diagnostic triad of Vohwinkel Syndrome includes: difuse and transgrediens palmo-plantar hyperkeratosis, constricting bands on the digits of the hands or feet (pseudoainhum) and hyperkeratotic papules on elbows and knees that might be associated with deafness.

KEY WORDS: Palmo-plantar keratoderma, deafness, genetics, connexins, Vohwinkel Syndrome.
Correspondencia:

Miguel Allevato

Email:

divisiondermatologia@gmail.com

Recibido: 27/07/2016

Aceptado: 02/04/2017

Conflictos de interés:

No se reportan conflictos de interés.

Financiación:

Ninguna. 


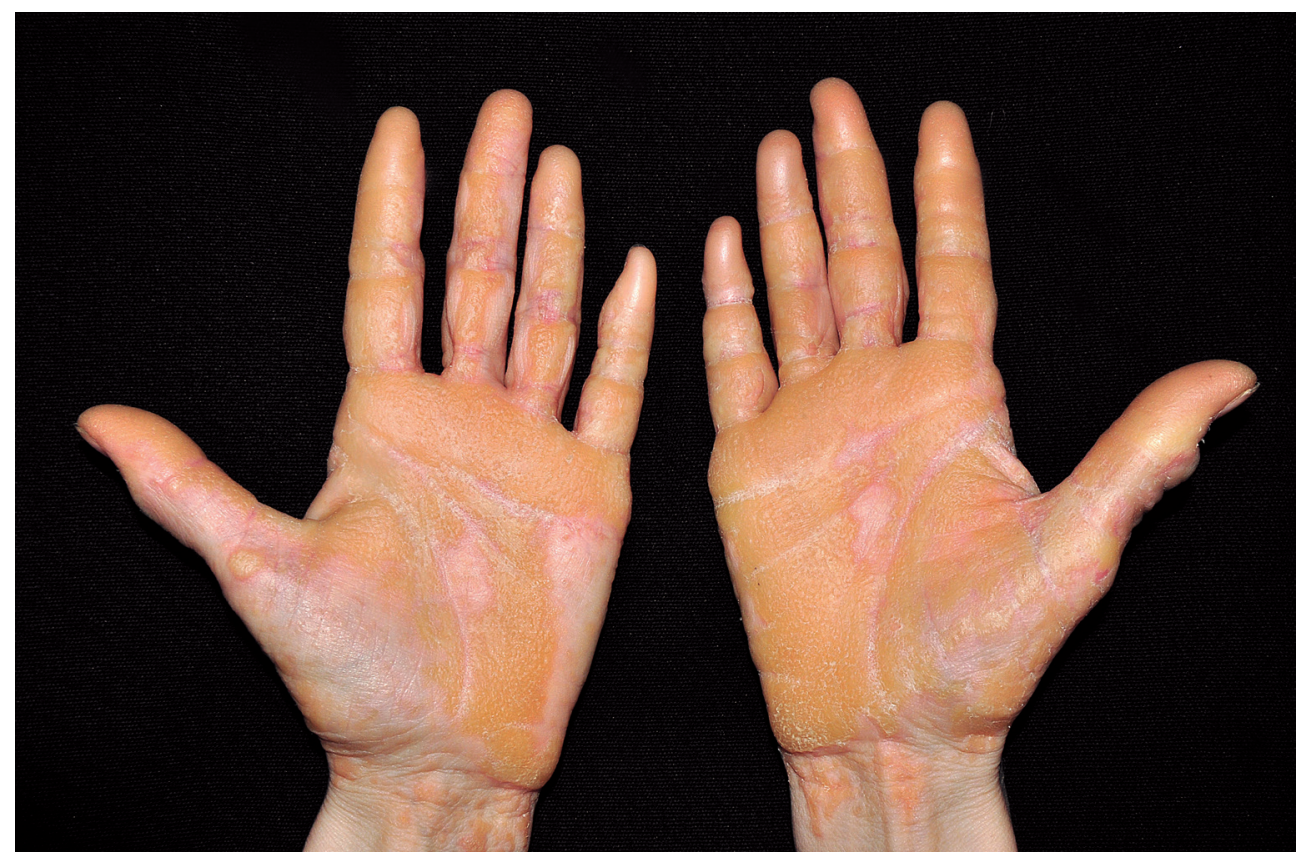

Figura 1. Queratodermia palmar difusa, transgredens. Se observan bandas constrictivas (pseudoainhum) en el cuarto y quinto dedos de ambas manos.

\section{INTRODUCCIÓN}

Las queratodermias palmo-plantares representan un grupo variado de trastornos hereditarios o adquiridos, cuya característica es la hiperqueratosis de la piel de las palmas, de las plantas o de ambas ${ }^{1}$.

Se ha demostrado que las mutaciones en los genes de las conexinas dan lugar a queratodermias palmo-plantares hereditarias. Entre ellas se encuentra el síndrome de Vohwinkel, genodermatosis ocasionada por mutaciones en el gen GJB2, que codifica para la conexina $26^{1}$.

\section{CASO CLÍNICO}

Se trata de una mujer de 67 años con antecedentes de hipotiroidismo de 15 de evolución en tratamiento con levotiroxina, e hipoacusia grave diagnosticada al año de vida.

No se pudieron recabar antecedentes familiares de importancia debido a que la paciente no conoce a su familia biológica; no tiene hijos.

El motivo de consulta fue la caída difusa del pelo del cuero cabelludo de 6 meses de evolución.

En el examen físico dermatológico se encontraron hiperqueratosis difusa en las palmas y en las plantas, que se acentuaba sobre los puntos de presión; en las manos se extiende a las caras laterales y a la flexura de las muñecas, con aspecto de "panal de abejas" (figura 1); además, bandas constrictivas en las falanges proximales del cuarto y quinto dedos de ambas manos (figura 2), y pápulas hiperqueratósicas “en estrella de mar" en el dorso de las manos y las rodillas con disposición lineal (figura 3).

En el estudio histopatológico de la biopsia de la cara lateral externa de la mano izquierda y de la rodilla del mismo lado se informó hiperqueratosis en la epidermis sin evidencia de actividad inflamatoria y, en la dermis, leve infiltrado inflamatorio mononuclear. Con la técnica de azul Victoria se evidenciaron fibras elásticas de características conservadas.

\section{"Se ha demostrado que las mutaciones en los genes de las conexinas dan lugar a queratodermias palmo- plantares hereditarias."}




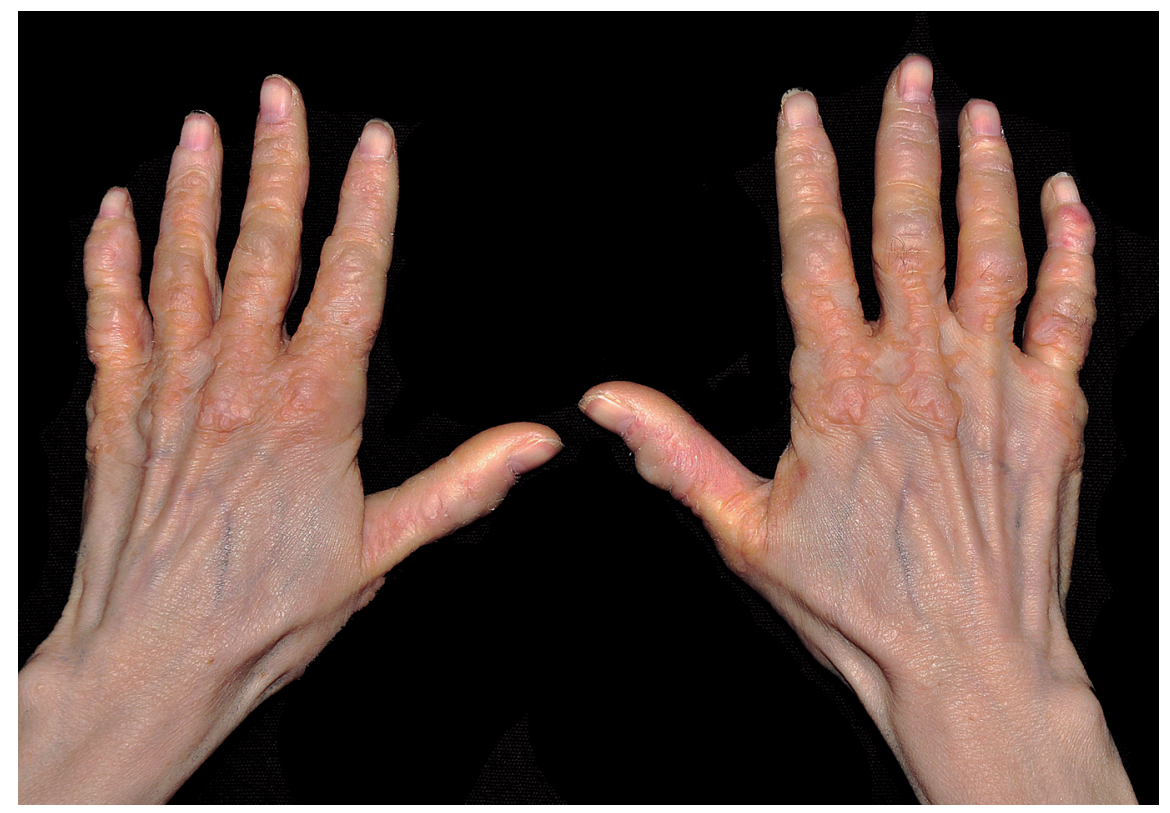

Figura 2. Hiperqueratosis en 'estrella de mar' en el dorso de ambas manos, pseudoainhum en el cuarto y quinto dedos de ambas manos.

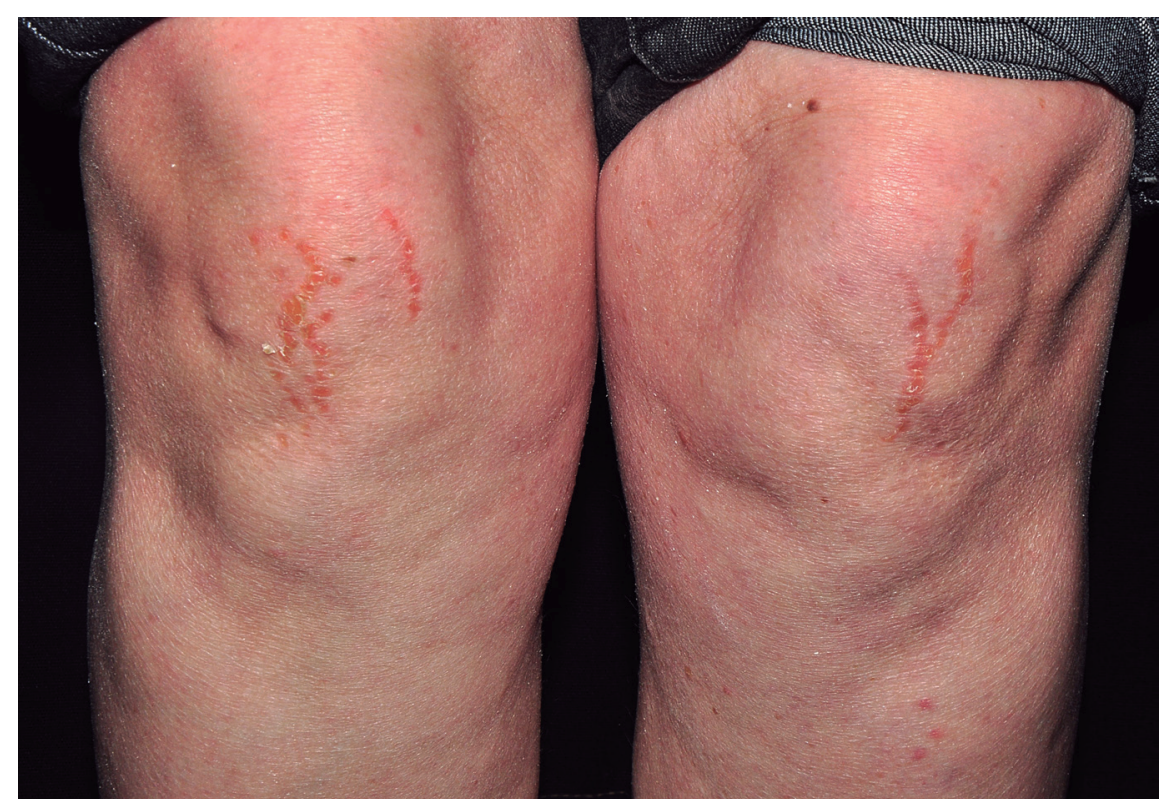

Figura 3. Pápulas queratósicas con disposición lineal en ambas rodillas.

Con el diagnóstico de síndrome de Vohwinkel se practicó audiometría que confirmó la hipoacusia profunda, y se indicó tratamiento con urea al $40 \%$ en palmas y plantas, y shampoo y loción capilar fortalecedora con aminoácidos para el cuero cabelludo, con buena tolerancia y respuesta.

\section{DISCUSIÓN}

El síndrome de Vohwinkel, también denominado queratodermia hereditaria mutilante", fue descrito en la literatura alemana en 1929 por Vohwinkel ${ }^{2,3}$.

Es una genodermatosis de herencia autosómica do- 
minante, ocasionada por mutaciones en el gen GJB2, en el locus 13q11-q12 que codifica para la conexina 26 (CX26) ${ }^{1,4,5}$. Las conexinas son proteínas integrales de membrana que componen las uniones comunicantes (gap junctions).

Se denominan "conexinopatías" al grupo de enfermedades genéticas asociadas a las conexinas. Algunas de ellas se expresan en varios tipos de células, mientras que otras muestran un patrón más restrictivo ${ }^{6}$. Es por eso que los trastornos de las conexinas pueden presentar una amplia variedad de manifestaciones clínicas que afectan la piel, los anexos, el sistema nervioso periférico o el oído ${ }^{1,3}$.

Cinco conexinas (CX) se expresan en la epidermis y sus anexos, a saber, CX 43, 26, 30, 30.3 y 31. Desempeñan un importante papel en la proliferación y diferenciación de la epidermis.

La CX26 sólo se ha identificado en las capas proliferativas de la piel, en las glándulas sudoríparas y en el epitelio de la córnea ${ }^{6}$. También es necesaria para la audición a nivel del órgano de Corti ${ }^{6}$.

En 1999, Maestrini et al. demostraron de forma concluyente el papel de la CX26 en el síndrome de Vohwinkel, y la mutación más común es una sustitución heterocigota (D66H) en el primer dominio extracelular de la CX26, en el gen GJB2, localizado en el cromosoma 13 (locus 13q11-q12) ${ }^{1}$.

El síndrome de Vohwinkel se manifiesta desde la infancia y se hace más evidente en la edad adulta, con predilección por el sexo femenino y la raza caucásica ${ }^{7}$ 9.

Clínicamente se caracteriza por una tríada ${ }^{4}$ :

- hiperqueratosis palmo-plantar difusa y simétrica, 'en panal de abejas', que comienza en la infancia temprana, durante la lactancia, y progresa hacia las muñecas y se desborda hacia las caras laterales y el dorso de las manos y los pies, es decir, se hace transgredens 1,5;

- bandas constrictivas alrededor de los dedos (pseudoainhum) que aparecen a continuación, también du-

\section{"El síndrome de Vohwinkel es} una rara genodermatosis de herencia autosómica dominante, ocasionada por mutaciones en el gen GJB2, que codifica para la conexina $26 . "$ rante la infancia temprana, después de algunos años del inicio de la queratodermia, especialmente en el quinto dedo; son bandas fibrosas en las articulaciones de las falanges que provocan estrangulamiento en forma gradual, pudiendo ocasionar mutilaciones, con mayor frecuencia durante la adolescencia y en la edad adulta $^{1,5,7}$, y

- pápulas queratósicas en 'estrella de mar' que se dan sobre los nudillos de los dedos de las manos y de los pies, en los codos y en las rodillas donde pueden adoptar una disposición lineal ${ }^{1,7,9}$.

Otras manifestaciones clínicas que pueden hallarse en el síndrome de Vohwinkel son ${ }^{1,7-9}$ :

- sordera: hipoacusia de percepción progresiva, moderada a grave;

- alopecia cicatricial y no cicatricial;

- alteraciones en las uñas: distrofia, e

- ictiosis: existe una variante del síndrome de Vohwinkel clásico, que asocia la ictiosis con la queratodermia palmo-plantar, pero cursa sin sordera. Se denomina síndrome de Camisa y se origina en una mutación del gen de la loricrina, localizado en el cromosoma 1 (1q21) ${ }^{9,10}$.

La paciente aquí reportada refería haber comenzado con la queratodermia palmo-plantar hacia el año de vida, con posterior aparición de las pápulas queratósicas en el dorso de las manos y en las rodillas durante la infancia, y de las bandas constrictivas durante la adolescencia. La hipoacusia profunda fue diagnosticada al año de vida. Ya en la edad adulta comenzó a notar la caída difusa del pelo del cuero cabelludo. No presentó alteraciones ungulares ni ictiosis.

Los hallazgos histopatológicos no son específicos: hiperqueratosis ortoqueratósica, hipergranulosis, acantosis con papilomatosis y, en ocasiones, un infiltrado crónico leve en la dermis superficial ${ }^{1,11}$.

El diagnóstico del síndrome se establece con base en los antecedentes familiares (árbol genealógico), el cuadro clínico, el estudio histopatológico y los exámenes genéticos. En el caso de nuestra paciente, la clínica resultó compatible, así como el estudio histopatológico. Sin embargo, no fue posible averiguar los antecedentes familiares debido a que se desconoce familia biológica de la paciente. El estudio genético no se pudo realizar. Los diagnósticos diferenciales del Síndrome de Vohwinkel son otras queratodermias palmo-plantares hereditarias, autosómicas dominantes de tipo difuso con características asociadas como ${ }^{1,3,11}$ :

- El síndrome de Bart-Pumphrey: es una queratodermia palmo-plantar variable y leve, asociada a las almohadillas de los nudillos, leuconiquia y sordera neurosensorial. 
- La queratodermia palmo-plantar con sordera neurosensorial: es de inicio en la primera infancia asociada a sordera neurosensorial progresiva.

- El síndrome de Huriez: es una queratodermia palmoplantar no transgredens con esclerodactilia, alteraciones ungulares y degeneración maligna de la piel afectada.

- El síndrome de Clouston (displasia ectodérmica hidrótica): es una queratodermia palmo-plantar con hipotricosis del cuero cabelludo, cejas, pestañas, axilas y pubis, y distrofia ungular.

- El síndrome de Olmsted es una queratodermia palmoplantar mutilante con placas hiperqueratósicas y eritematosas periorificiales (periorales y perigenitales).

No existe un tratamiento específico ni definitivo para el síndrome de Vohwinkel. La terapéutica va dirigida a la disminución de la queratodermia y a la prevención de las autoamputaciones de las falanges de los dedos, que es la complicación más incapacitante para el paciente ${ }^{7,8}$.

Se han obtenido resultados pobres con los tratamientos con queratolíticos tópicos, corticoides intralesionales y dermoabrasión ${ }^{4}$.

Los retinoides orales (etretinato, isotretinoína y acitretín) han sido empleados con cierto éxito, tanto para la hiperqueratosis como para las bandas constrictoras. Sin embargo, las lesiones reaparecen rápidamente al suspender la medicación, por lo que el tratamiento debe ser continuo ${ }^{4}$.

Las bandas fibrosas pueden extirparse quirúrgicamente 5; a pesar de ello, la corrección quirúrgica aporta una mejoría transitoria y a corto plazo, con alto riesgo de recidivas, por lo que se reserva para aquellos pacientes con compromiso neurovascular digital ${ }^{7,8}$.

Como en todas las genodermatosis se debe establecer asesoría genética.

La paciente en este caso recibió un tratamiento con queratolíticos locales (urea al $40 \%$ ) en palmas y plantas, y shampoo y loción con aminoácidos para el cuero cabelludo.

\section{CONCLUSIONES}

El síndrome de Vohwinkel es una rara genodermatosis de herencia autosómica dominante, ocasionada por mutaciones en el gen GJB2, que codifica para la conexina 26.

Es el dermatólogo quien debe conocer y reconocer esta entidad a fin de realizar un pronto y certero diagnóstico para mejorar la calidad de vida del paciente, prevenir complicaciones, evitar secuelas físicas y funcionales y realizar el adecuado consejo genético.

\section{REFERENCIAS}

1. Krol A. Queratodermias. En: Bolognia J, Jorizzo J, Rapini R, et al. editores. Dermatology. New York: Ed. Elsevier; 2004. p. 809-21.

2. Vohwinkel K. Keratoderma hereditarium mutilans. Arch Dermatol Syphil. 1929;158:354-64.

3. Bobbio L, Tejada E. Queratodermias palmo-plantares. Dermatología Peruana. 2009;19:130-43 .

4. Velasco-Vaquero E, González-López A, PozoRomán T. Evolución de un síndrome de Vohwinkel tratado con retinoides orales. Med Cután Iber Lat Am. 1999;27:97-8.

5. Gianetti A, Cavalleri R. Queratodermias palmoplantares hereditarias. En: Fitzpatrick T, Freedberg I, Eisen A, et al. editores. Dermatología en Medicina General. Buenos Aires: Editorial Panamericana; 2001. p. 1433-43.

6. Barrio L, González-Nieto D. Conectados por conexinas: comunicación intercelular mediada por canales de conexinas y enfermedades asociadas a mutaciones en los genes de conexina. Consolider. 2012;1:1-10.

7. Sinha M, Watson SB. Keratoderma hereditarium mutilans (Vohwinkel syndrome). JHS. 2009;34:235-7.

8. Bassetto F, Tiengo C, Sferrazza R, Belloni-Fortina A, Alaibac M. Vohwinkel syndrome: Treatment of pseudoainhum. Int J Dermatol. 2010;49:79-82.

9. Dalla Corte L, Scribel da Silva MV, Flores de Oliveira C, Vetoratto G, Bissacotti Steglich R, Borges J. Vohwinkel syndrome, ichthyosiform variant by Camisa, case peport. An Bras Dermatol. 2013;88:206-8.

10. Hernández-Martín A. Avances biomoleculares en los trastornos epidérmicos hereditarios. Actas Dermosifiliogr. 2005;96:203-16.

11. Weedon D, Stuttron G. Trastornos de la maduración y queratinización epidérmica. En: Weedon D, Stuttron G, editores. Piel. Patología. Madrid: Ed. Marbán; 2002. p. 235-66. 